\title{
Emotional responses in augmented reality based M-learning applications using Kansei engineering for secondary school students
}

\author{
Farah Asyikin Jasmy ${ }^{1}$, Fauziah Redzuan ${ }^{2}$, Rogayah Abdul Majid ${ }^{3}$, Norisan Abd Karim ${ }^{4}$ \\ ${ }^{1,2,3,4}$ Faculty of Computer and Mathematical Sciences, Universiti Teknologi MARA (UiTM), Malaysia \\ ${ }^{1}$ Connexion Sdn Bhd, Malaysia
}

\section{Article Info \\ Article history: \\ Received May 31, 2021 \\ Revised Oct 20, 2021 \\ Accepted Oct 28, 2021}

\section{Keywords:}

Augmented reality

Emotion

Emotional response

Kansei engineering

Mobile learning

\begin{abstract}
Design that evoked emotions are one of the main concerning issues in developing mobile applications for online learning in general and for augmented reality (AR) based mobile learning applications in specific. Emotional design could attract users by creating different feelings while using AR-based mobile learning applications. Suitable emotions related to design could motivate students towards fascinating learning experiences. The aim of this research is to evaluate the emotional responses of the students based on different designs in AR-based mobile learning applications using Kansei engineering technique. In this research, about thirty-two students from secondary school were involved in an experiment to identify the Kansei (emotion) words for AR-based mobile applications. The data gathered were analysed using factor analysis (FA), principal component analysis (PCA), and partial least square (PLS) analysis. The results revealed four important pillars of emotions or known as Kansei semantic space such as challengingthinking, motivated, humorous, preoccupied and also touched as an additional pillar. Based on the PLS analysis of design elements of AR-based mobile learning applications suggested specific design and emotions based on the pillars. In conclusion, this research is motivated to give affective formulae that would guide the design of AR-based mobile learning materials in the future.
\end{abstract}

This is an open access article under the CC BY-SA license.

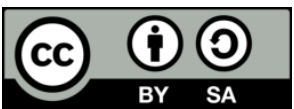

\section{Corresponding Author:}

Fauziah Redzuan

Faculty of Computer and Mathematical Sciences

Universiti Teknologi MARA (UiTM)

Shah Alam, Selangor, Malaysia

Email: fauziahr@tmsk.uitm.edu.my

\section{INTRODUCTION}

E-learning is defined as a new and modernized learning method that has replaced the traditional classroom system [1]. Internet is a good tool in e-learning because it helps to facilitate learning platforms virtually with others from all over the world by conducting webinar (live online classes) or by communicating via chats and message forums. However, as e-learning is conducted online, facial expressionism is unable to be conveyed, as well as body recognition, and reaction of the students as compared to face to face learning method [2]. Augmented reality (AR) technology has been utilized in many fields, like pharmaceutical, craft simulations, production, education, robotics, gaming, recreation and machine repair [3]. Of late, AR has become important in the education field [4]. Several studies showed that $\mathrm{AR}$ is now ready to enhance teaching an learning process [5]. AR is additionally ready to encompass the 
mixing of digital learning resources in 3-dimension (3D) type with real world [5]. As an example, by using AR, it enables the learner to explore scientific phenomenon in chemistry such as chemical bond [6]. As technology changes to educational landscape, improving learning experience can attract and sustain learner's interest. The emotion in computer-supported learning could affect learner's performance and achievement, as revealed by previous researches [7]. Learning and achievement that are attached with motivation, attention and self-regulation can give immediate effect with emotions as agreed by [8]. Positive emotion state could help learners in learning process [9]. As constructed by Nagamachi [10], Kansei engineering (KE) is an ergonomic consumer-oriented technology which has been successfully used to assimilate the emotional interest in product design. KE methods can be used as emotional factors for AR-based online learning to find the relations between design elements and emotions. Empirical findings indicate KE method in evaluation process to AR-based online learning in this research.

A preliminary study has been conducted by using questionnaire for students aged 16 until 21 years old. The aim of this preliminary study is to understand the problem faced by the students in learning. The total responses are 32 which is $60 \%$ from female and $40 \%$ from male students. As for the education backgrounds, $93.3 \%$ of the respondents are from secondary school and $6.7 \%$ from college/university. This questionnaire highlights enquiries on three most difficult subjects which are biology, chemistry and physics. The result shows that chemistry subject is about $28.1 \%$ lower than biology which achieved $34.4 \%$. About 73.3\% students know about AR. From the result, 53.3\% students have utilised AR using mobile applications for education. However, only 53.8\% of the students are satisfied in their experience of using AR.

Emotions design is important so that the students can experience the subject with positive emotions [11], [12]. Apart from that, AR is one the tools for effective education to help teachers in classroom [13]. Due to this, AR-based learning must be designed in order to gain students' interactions, motivation, and satisfaction to ensure student's engagement for better understanding [14]. In addition, based on preliminary study, about $28.1 \%$ students agreed that chemistry subject is one of the difficult subjects in school. This research focuses more on chemistry subject because students' imagination is limited, and it is hard for them to imagine how particles such as atoms compose substances [15]. Last but not least, the aim of this study is to evaluate students' emotional responses based on their interactive learning experience using augmented reality-based mobile learning material. This study involves secondary school that responses on chemistry subject apps in PlayStore.

\section{LITERATURE REVIEW}

The definitions of emotion are a multiplex expertise of behavior, consciousness and bodily sensation that indicates the personal importance of issue, a state of affairs or an event [16]. As children develop, their improvement is generally associated with the components of emotional ability which is mirrored within the competency to understand precisely and manage their own and other's emotion [17]. School children mostly have nonheritable skills and explicit primary emotions (such as anger, joy, fear and sadness) and secondary emotions (such as guilt, pride and shame), therefore explicit emotions and variance in their knowledge becomes great [18], [19].

AR could be a with-it technology that enables the user to watch world objects complemented with computer-created objects [20]. Lately, AR experiences are delivered on mobile phones. Mobile augmented reality (MAR) is outlined as AR generated and retrieved with mobile devices in mobile environments. MAR presents information concerning the necessary surroundings that is integrated into the $3 \mathrm{D}$ area of that atmosphere. Hence, there has been a considerable apprehension over the use of rising technology to support learning method. Certainly, AR, and several various technologies that are unified within the instructional pitch, like the utilization of simulations, e-learning, computer, internet, multimedia, social web and additional recent mobile devices and immersive environments such as games, virtual worlds and AR [21], [22].

Learning and teaching ways have been influenced by trendy technologies. These methods can still modify dramatically within the recent years. One thing, however, that will remain similar is the capability of the teacher, whether human or machine to carry the fundamental concepts to the learner. Conferring to [23], AR is characterized by accumulation computer-generated info that is layered into the important things, that ends up in AR. Furthermore, most of MAR learning-based systems additionally focus on games or simulation. The flexibility of mobile device that has the options and properties like moveableness, social interactivity, property, context sensitivity and individuality [24] has created a learning expertise in the area. By merging virtual and real worlds together, it has produced new potentials in enhancing the standard of teaching and learning activity. The effectiveness of AR can be more extended once the application is mixed with alternative style of technologies like mobile device.

According to [25], AR has the power to encourage proprioception learning. Moreover, since AR uses 3D registration of virtual and real objects, it lets the user read the training content during a 3D

Emotional responses in augmented reality based M-learning applications using ... (Farah Asyikin Jasmy) 
perspective. This affordance will facilitate students who struggle to envision the phenomena that don't seem to be potential to be shown within the universe or if the construct is simply too advanced. As urged by [26], AR games will stimulate student's previous information and increase the student's level of engagement in educational activities. E-learning system will embrace intuitive interaction by using the augmented reality. Academic content is toughened through a large sort of media, starting from non-interactive books to extremely interactive digital experiences that totally have interaction with the user's sense.

There is one type of theory and two models of emotions which are control-value theory, circumplex model and orthony, Clore and Collins model. Control-value theory is based on three dimensional taxonomies as mentioned in [27], the process of three-dimensional taxonomy is to differentiate the outcome with activities which completes the dimension such as positive and negative reaction for the activities that leads to outcomes from activities. A circumplex model is ideal once it views totally different emotional states as a result that they'll all be incontestable alongside their relative relationships. This model was created to point out that emotions' square measures nuance and not become utterly independent from each other. According to [27], they developed system that associates with artificial intelligent (AI) to express feelings in computer. The system manipulates the computer's feelings by using three aspects which are events, agents and objects. For instance, if something happens with sad events, the agents react to the event whether it approves or rejects the sad events and objects react as dislike or like the sad events.

There are four types of emotion measurements which are product emo measurement instrument (PreEmo), self-assessment manikin (SAM), Kansei engineering and bio-signals. PreEmo is a non-verbal emotion illustrated by animations of vocal, bodily and dynamic facial expression. For instance, respondents express their emotions with 14 emotion cartoons which is pleasant such as amusement, surprise and inspiration while the unpleasant ones such as yearning, disgust and disappointment. SAM is known as interactive computer program before its changes to use pencil-and-paper version for mass screening in a group. Kansei is the impression that somebody gets from a specific unit, setting or using all the senses of sight, hearing, feeling, smell, and style as the information. Ulterior complicated mind pattern is created and kept at intervals like the human brain containing all the older impressions, building the inspiration of human behaviour. Bio-signals is human body reaction emotions. Human body has two types of involuntary system which are parasympathetic division and sympathetic division. KE is chosen in this research because it emphasises to understanding the entire product expertise from psychological feature and emotional views. Moreover, many researchers have proven that KE method can produce the product design with psychological features.

\section{RESEARCH METHOD}

The present research adopted the use of KE methodology. This procedure becomes very eminent in order to determine and analyse information regarding the responses of emotion. The term Kansei is a word emanated from Japanese language, which in English Language can be referred to as consumer's psychological feeling and image [28]. It is used by a person as an impression or recognition of a particular artefact, condition or environment through various senses of hearing, feeling, taste, sight, smell. Also, KE could be used to translate the impressions, feelings, and demands of consumers on available product or concepts into design solutions as well as concrete design parameters [29].

There are three types of classification of the KE procedure: KE type I, type II and type III, respectively. Mitsuo Nagamachi stated that KE type I can be a form of classification on a new product embedded in the design elements. On the other hand, KE type II employs the available computer technologies, ranging from statistical analysis, expert system, genetic algorithm, and neural network. While, type III can be said in terms of a mathematical model mainly for built in malice of the rule-based uses in deriving the ergonomic result from Kansei words. In the cause of this procedure, a mathematical model will entail a type of logic that plays the same role to the rule-based. As such, KE type that will be suitable for the present study would be KE type II.

Overall, KE type II method is adapted for the present study from [30]. The initial phase employed was based on Figure 1 which focuses on identifying the problem. In achieving this, a comprehensive review of the literature was carried out on the topic involving student's emotions during online learning, particularly the one which has to do with augmented reality and issues. These are originally derived from the interview sessions carried out while conducting the study's preliminary investigation. Afterward, the identification of problem becomes the following phase which entails phases in KE type II. Nevertheless, in the cause of phase 1 , the step carried out identifies important emotions during online learning environment. The main idea of this phase focuses on checking Kansei in desire, feelings, or emotion, towards a desired product of the ARbased mobile learning apps. The objective of the phase 2 involves identifying emotion design elements for

Indonesian J Elec Eng \& Comp Sci, Vol. 24, No. 3, December 2021: 1846 - 1854 
certain emotions which will be the main focus in the current research. As such, KE Type II method by [30] was adapted For Phase 2 of the current study.

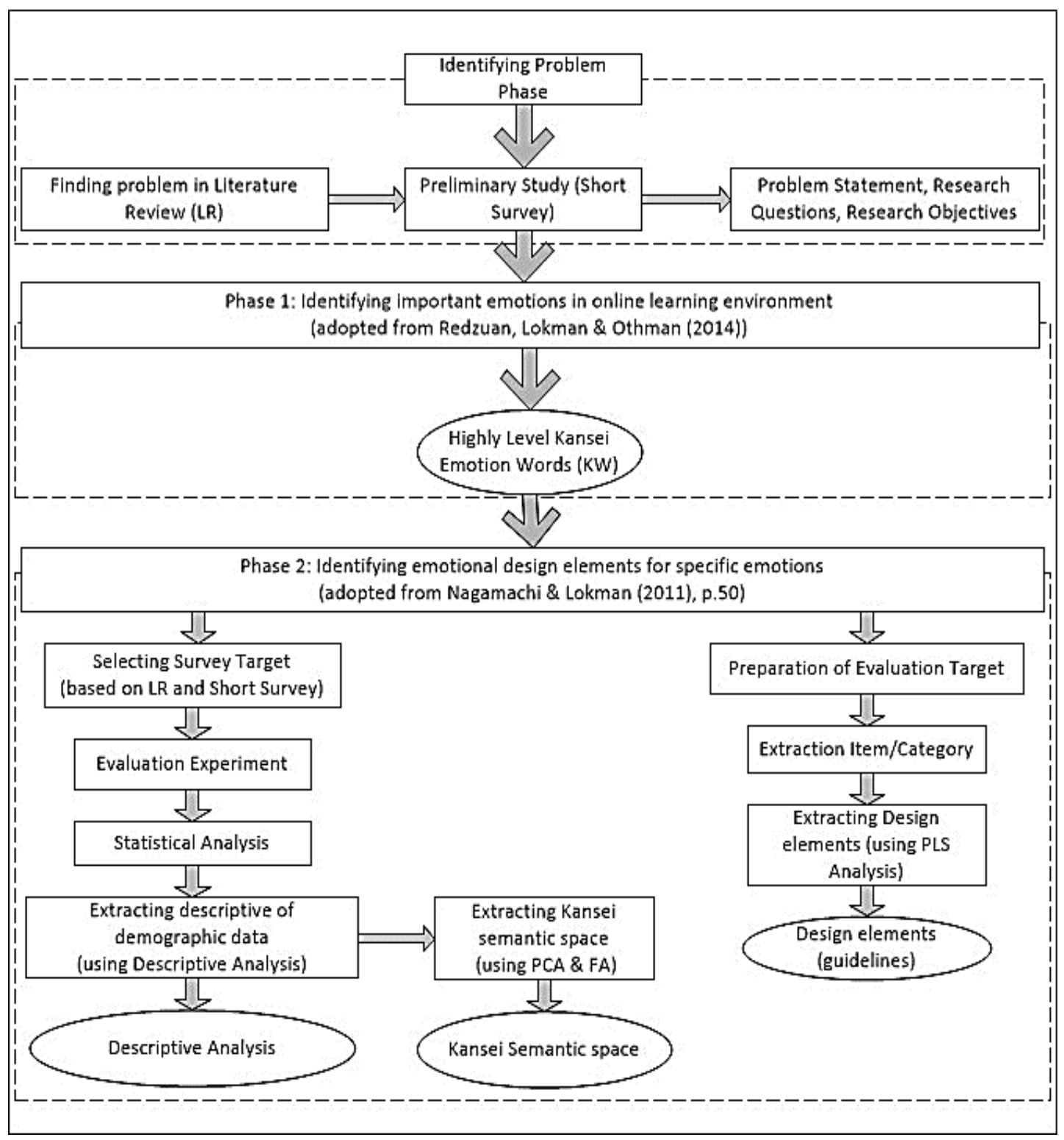

Figure 1. An overview of overall research methodology phases using KE type II method

\section{RESULTS AND DISCUSSION}

The present research employed Kansei Engineering technology via quantitative method, thus three set of data were formed from the evaluation experiment. Firstly, there were 55 sets of Kansei (emotion) responses from 32 participants for the dependent variables (y). Secondly, eight design specimens are identified in the sample of augmented reality-based learning. Thirdly, this design elements are also included in the independent variables (x). However, three categories of analyses were performed in the current research. These are: descriptive analysis, principal component analysis (PCA) with factor analysis (FA) and partial least square (PLS). The demographic data employed the use of descriptive analysis, while PCA and FA exploration of the Kansei semantic space involved the paramount emotions for Augmented Reality-based online learning. Thereafter, the design elements employed the PLS to examine the identified emotions. Based on this, determining appropriate method of analysis is identified as important in order to derive the best result. Ishihara and Ishihara [31] stated that statistical consideration of SD data of the AR mobile-based online learning data has 32 subjects $\times 8$ specimens $\times 55$ Kansei words $=14,080$ evaluations.

Emotional responses in augmented reality based M-learning applications using ... (Farah Asyikin Jasmy) 
Typically, multivariate data is normally employed as design experiments or data collection schemes [32]. Therefore, multivariate analysis was seen as a suitable for evaluation experiment in analysing AR mobile- based learning data in the present study. Overall, the multivariate analysis was used to calculate the average amount of raw data for all specimens and each Kansei word. As stated by [33], a principal component analysis was carried out as multivariate techniques mainly to determine the semantic data for Kansei emotion in AR mobile-based used in online learning. Similarly, the PCA employed in the present study represents the relation between the Kansei emotion and the specimens.

As shown in Figure 2, the PCA of the Kansei words and specimens reveal that mostly positive words are seen on the right $\mathrm{x}$-axis, while the negative words are seen to the left of $\mathrm{x}$-axis. The implication of this is that the semantic space for majority of the positive emotions words is represented by challenging thinking. Furthermore, emotion words, for instance self-confident, ambiguous as well as humorous are plotted at the top part of the y-axis. This implies humorous as the semantic space as seen in this axis. Also, Kansei semantic space of challenging thinking as well as humorous in specimens 6 could possess the design elements that is most suitable for these Kansei emotions, whereas there could be consideration for specimens 4, 5 and 7 to be appropriate in positive emotions' design. Nevertheless, both Kansei semantic spaces; humorous and challenging thinking are constructed on the dimension of Factor 1 and 3 respectively. However, challenging-thinking could be specimens 6 and 7, but specimens 5 are found to be not very humorous.

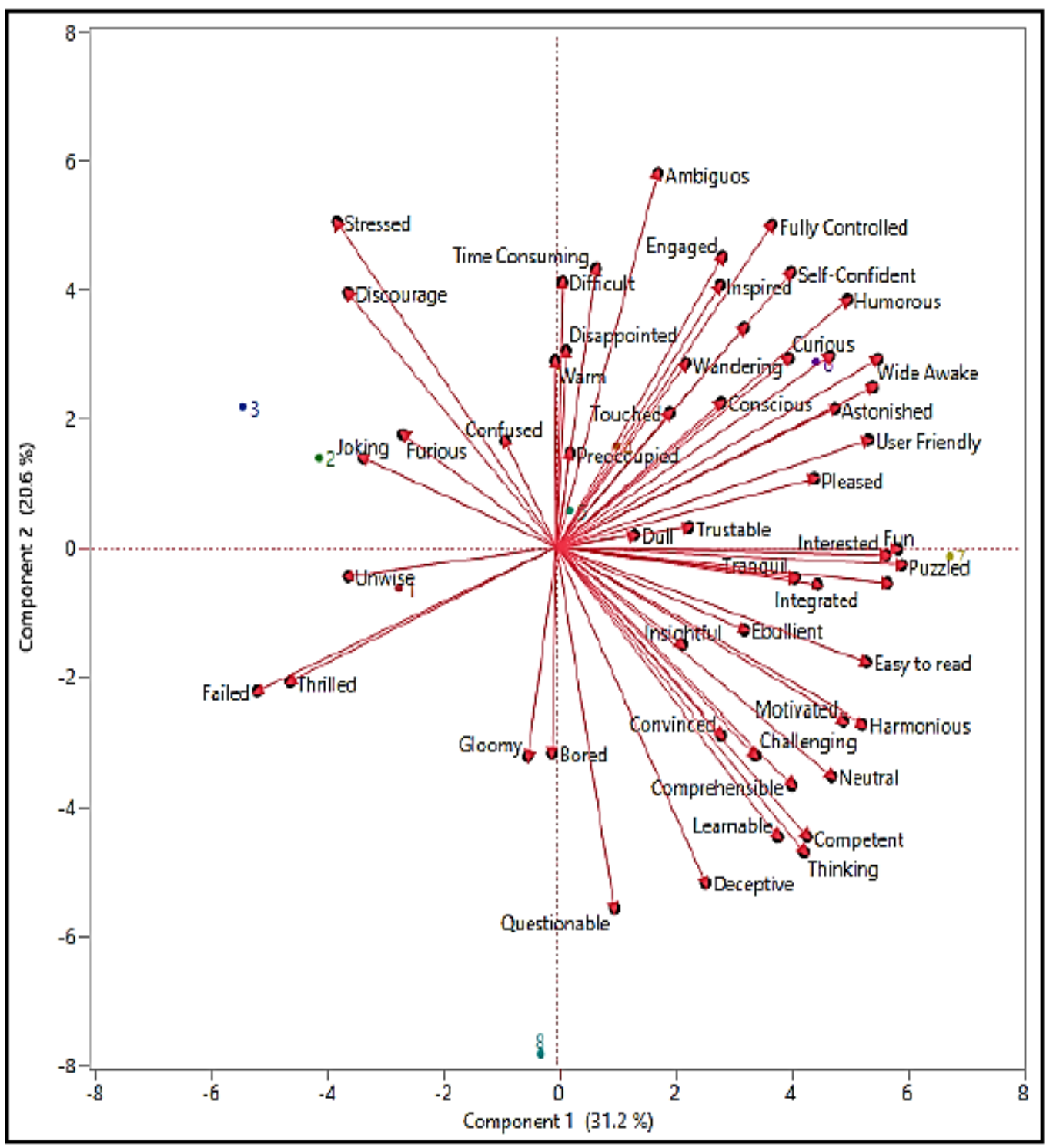

Figure 2. Principal component analysis of Kansei words and specimens 
As presented in the factor analysis (FA) result in Table 1, there several factors or pillars which are identified in AR-based learning materials semantic space. There are four main pillars of emotions or Kansei which are challenging-thinking, motivated, humorous and preoccupied. This followed an additional pillar that is recognized as touched.

Table 1. Partial view of the factor analysis (FA) of the emotion (Kansei) words

\begin{tabular}{cccccccc}
\hline Emotions & Factor 1 & Emotions & Factor 2 & Emotions & Factor 3 & Emotions & Factor 4 \\
\hline Challenging & 0.9657 & Learnable & 0.9067 & Fully Controlled & 0.8988 & 0.8945 \\
Comprehensible & 0.9204 & Neutral & 0.8876 & Humorous & 0.8882 & Disappointed & 0.8738 \\
Harmonious & 0.9052 & Easy to Read & 0.7681 & Time Consuming & 0.8290 & Curious & 0.8048 \\
Deceptive & 0.8820 & Motivated & 0.7293 & Pleased & 0.7798 & Preoccupied & 0.7901 \\
Convinced & 0.8749 & Puzzled & 0.7200 & & & \\
Thinking & 0.8167 & & & & & \\
Competent & 0.7686 & & & & & \\
\hline
\end{tabular}

The first pillar is known as challenging-thinking which encompasses the Kansei words such as challenging, comprehensible, harmonious, thinking and others. The second pillar is identified as motivated and includes the Kansei words such as learnable, easy to read and others. Humorous is the third pillar and it includes the Kansei words such as fully controlled, pleased and others. Fourth pillar on the list is preoccupied and involves Kansei words like disappointed, curious and others. The remaining additional pillar, touched comprises of astonished and warm.

Nevertheless, there exist similarities of the present study's result compared to previous related work. As such, there is the similarity between the Kansei word challenging-thinking and the second factor in [34]. Similarly, the Kansei word motivated is also same with first factor in [35], that is fun-motivated. Furthermore, Kansei word such as humorous is also similar with fourth factor in [34]. As expected, Kansei word preoccupied is also same with fourth factor in [35]. The additional Kansei word of touched was also found to be the same with the third factor in [34]. Overall, this could be an outcome of different domain in this investigation. However, the Kansei word of motivated in the present research has various common emotions with other previous works. As a result, motivation becomes eminent for students during the process of online learning [35].

Conversely, the analysis of the relationship between Kansei and design was found to be suitable to be using partial least square (PLS). This is because PLS is capable of identifying the design elements of ARbased online learning medium for Chemistry subject that are important to certain emotions. Additionally, PLS is employed mainly to dictate the dominant elements of design in existing in specific emotion which are revived by every specimen.

Nevertheless, in order to investigate the design elements for 8 specimens, the present study used quantification theory types III (QT3) method for 8 specimens that construct 19 elements of design and 41 values prior to the experiments as well as before the analyses were done. As mentioned by [36], QT3 method is utilized to determine the relationship existing among multivariate categorical data that employ the term item for a variable, including category for the differential of a variable. Therefore, the classification of all the elements (item/category) and their conversion into dummy variables was initially done in order to carry out PLS analysis. This is followed by combining the average value of the five main group factors characteristic one after another that have been determined from past analysis.

Furthermore, in order to identify the influence of the good and bad design, the present study carried out PLS Range for every emotion representing each of the factor groups of five factors. As such, the PLS range formula: PLSRange $=$ PLSMax - PLSMin was employed. This PLS range formula as shown was used to determine each element of design as well as value in every emotion. Table 2 contains the design element column and also the value column. As shown, there exist two sub columns in design element which are item and category of every specimen. Similarly, there exist two sub columns for value column which are PLS value of emotion and PLS Range. In order to calculate PLS Range there is need to firstly sort the PLS result out in a descending order to derive a dominant design element for certain emotion. Thereafter, to the selection of the largest positive value of category was done to show the elements that produce good result as well as the biggest negative value that designates the elements which produce bad design. As shown in Table 2, represents the partial view of the influential design elements' for Kansei (emotion) preoccupied result. 
Table 2. A partial view of the influential design elements for emotion "preoccupied"

\begin{tabular}{llcc}
\hline \multicolumn{1}{c}{ Design Element } & Category & PLS (preoccupied) & Value \\
& Small & -0.11289 & 0.46625 \\
Button Size & Medium & 0.30703 & \\
& Large & -0.15922 & 0.41975 \\
Number of Multimedia Elements & $>3$ elements & -0.20987 & \\
& $<=3$ elements & 0.20987 & 0.29383 \\
Number of Colors in 3D Object & $>3$ colors & 0.14691 & \\
& $<=3$ colors & -0.14691 & \\
\hline
\end{tabular}

\section{CONCLUSION}

This research has been conducted to identify the emotions responses of students evaluation in augmented reality-based m-learning course content and to specify the emotions related to the design elements of augmented reality-based m-learning course content. This research also carried out an experiment for the students to interact to the design of augmented reality-based learning in chemistry course using mobile applications. PLS analysis was utilized in this research to identify suitable design elements for each pillar. Thus, this study's findings had successfully achieved the aim for this research which is to evaluate students' emotional responses based on their interactive learning experience using augmented reality-based learning material. This research has successfully achieved the first objective by identifying the pillars of emotions suitable for the augmented reality-based m-learning course content (specifically for chemistry subject) using PCA and FA. Also, this research has achieved the second objective to identify the suitable design elements for each of the emotions using PLS.

Further research is suggested to explore other things not just online learning but others sector such as online shopping, online cooking and social media. Besides that, the findings of this study also provide the following insights for future research on other subjects such as Biology since android PlayStore application is used as the specimen involved in this research. Future works could use the IOS Apple App store applications.

\section{ACKNOWLEDGEMENTS}

We would like to thank the Faculty of Computer and Mathematical Sciences, Universiti Teknologi MARA (UiTM), Shah Alam, Selangor, Malaysia for the support given to this research.

\section{REFERENCES}

[1] P. Christensson, E-learning definition, TechTerms, 2015. Accessed: Jun. 4, 2018. [Online]. Available: https://techterms.com/definition/e-learning

[2] M. Zembylas, “Adult learners' emotions in online learning," Distance Educ., vol. 29, no. 1, pp. 71-87, May. 2008, doi: 10.1080/01587910802004852.

[3] O. Oda, L. J. Lister, S. White, and S. Feiner, "Developing an augmented reality racing game," in Proceedings of the 2nd International Conference on Intelligent Technologies for Interactive Entertainment, 2008, pp. 1-8.

[4] N. F. Saidin, N. A. Halim, and N. Yahaya, "A review of research on augmented reality in education: Advantages and applications," Int. Educ. Stud., vol. 8, no. 13, pp. 1-8, June. 2015, doi: 10.5539/ies.v8n13p1.

[5] H.-K. Wu, S. W.-Y. Lee, H.-Y. Chang, and J.-C. Liang, "Current status, opportunities and challenges of augmented reality in education," Comput. Educ., vol. 62, pp. 41-49, March.2013, doi: 10.1016/j.compedu.2012.10.024.

[6] N. F. Saidin, N. D. Abd Halim, and N. Yahaya, "Designing Mobile Augmented Reality (MAR) for Learning Chemical Bonds," in Proceedings of the 2nd International Colloquium of Art and Design Education Research ( $i$ CADER 2015), 2016, pp. 367-377, doi: 10.1007/978-981-10-0237-3_37.

[7] J. L. Lemke, "Thinking about feeling: Affect across literacies and lives," in Identity, Community, Learning Lives, Digital Age, ch. 4, pp. 57-69, Cambridge, UK: Cambridge University Press, 2013.

[8] R. Pekrun and E. J. Stephens, "Achievement emotions: A control-value approach," Soc. Personal. Psychol. Compass, vol. 4, no. 4, pp. 238-255, March. 2010, doi: 10.1111/j.1751-9004.2010.00259.x.

[9] A.-N. A. Khairuddin, F. Redzuan, and N. A. Daud, "Evaluating Students' Emotional Response in Augmented Reality-Based Mobile Learning Using Kansei Engineering," in International Conference on User Science and Engineering, 2018, pp. 79-89, doi: 10.1007/978-981-13-1628-9_8.

[10] M. Nagamachi, "Introduction of Kansei engineering," Tokyo Japan Stand. Assoc., 1996.

[11] S. W. Lawson, J. R. G. Pretlove, A. C. Wheeler, and G. A. Parker, "Augmented reality as a tool to aid the telerobotic exploration and characterization of remote environments," Presence Teleoperators and Virtual Environments, vol. 11, no. 4, pp. 352-367, August. 2002, doi: 10.1162/105474602760204273.

[12] H. Adnan and F. Redzuan, "Evaluating students' emotional response in video-based learning using Kansei Engineering,” 2016 4th Int. Conf. User Scie. Eng. (i-USEr), 2016, pp. 237-242, doi: 10.1109/IUSER.2016.7857967. 
[13] J. A. Muñoz-Cristóbal, I. M. Jorrín-Abellán, J. I. Asensio-Pérez, A. Martínez-Monés, L. P. Prieto, and Y. Dimitriadis, "Supporting Teacher Orchestration in Ubiquitous Learning Environments: A Study in Primary Education," in IEEE Trans. Learn. Tech, vol. 8, no. 1, pp. 83-97, 2015, doi: 10.1109/TLT.2014.2370634.

[14] M. Akçayır and G. Akçayır, "Advantages and challenges associated with augmented reality for education: A systematic review of the literature," Educ. Res. Rev., vol. 20, pp. 1-11, 2017, doi: 10.1016/j.edurev.2016.11.002.

[15] S. Cai, X. Wang, and F.-K. Chiang, "A case study of Augmented Reality simulation system application in a chemistry course," Comput. Human Behav., vol. 37, pp. 31-40, Oct. 2014, doi: 10.1016/j.chb.2014.04.018.

[16] R. C. Solomon, The Structure of Emotions, 2021. Accessed: Jun. 7, 2018. [Online]. Available: https://www.britannica.com/science/emotion

[17] S. A. Denham, "Social-emotional competence as support for school readiness: What is it and how do we assess it?," Early Educ. Dev., vol. 17, no. 1, pp. 57-89, 2010, doi:10.1207/s15566935eed1701_4.

[18] P. L. Harris, Children and emotion: The development of psychological understanding. New York, USA: Basil Blackwell, 1989.

[19] M. Lewis, "Self-conscious emotions: Embarrassment, pride, shame, and guilt," Handbook of emotions, pp. 742-756. 2008.

[20] R. T. Azuma, “A survey of augmented reality," Presence teleoperators virtual Environ., vol. 6, no. 4, pp. 355-385, Aug. 1997, doi: 10.1162/pres.1997.6.4.355.

[21] I. E. Dror, "Technology enhanced learning: The good, the bad, and the ugly," Pragmat. Cogn., vol. 16, no. 2, pp. 215-223, 2008, doi: 10.1075/pc.16.2.02dro.

[22] S. Martin, G. Diaz, E. Sancristobal, R. Gil, M. Castro, and J. Peire, "New technology trends in education: Seven years of forecasts and convergence," Comput. Educ., vol. 57, no. 3, pp. 1893-1906, 2011, doi: 10.1016/j.compedu.2011.04.003.

[23] L. Johson, R. Smith, H. Willis, A. Levine, and K. Haywood, The Horizon Report 2011, New Media Consortium, 2011. [Online]. Available : https://eduq.info/xmlui/bitstream/handle/11515/19536/2011-Horizon-Report-creativecommons-copy.pdf?sequence $=1$

[24] J. Huizenga, W. Admiraal, S. Akkerman, and G. ten Dam, "Mobile game-based learning in secondary education: engagement, motivation and learning in a mobile city game," J. Comput. Assist. Learn., vol. 25, no. 4, pp. 332-344, 2009, doi : 10.1111/j.1365-2729.2009.00316.x.

[25] C.-H. Chien, C.-H. Chen, and T.-S. Jeng, "An interactive augmented reality system for learning anatomy structure," in proceedings of the international multiconference of engineers and computer scientists, vol. 1, 2010, pp. 17-19.

[26] K. Squire and E. Klopfer, "Augmented reality simulations on handheld computers," J. Learn. Sci., vol. 16, no. 3, pp. 371-413, 2007, doi: 10.1080/10508400701413435.

[27] R. Pekrun, "A social-cognitive, control-value theory of achievement emotions," Advances in Psychology, vol. 131, pp. 143-163, 2000, doi:10.1016/S0166-4115(00)80010-2.

[28] M. Nagamachi, "Kansei engineering: the framework and methods," Kansei Eng., pp. 1-9, Tokyo, Japan: kaibundo publishing, 1997.

[29] N. S. Schutte, J. M. Malouff, and N. Bhullar, "The assessing emotions scale," in Assessing emotional intelligence, , pp. 119-134, 2009, doi: 10.1007/978-0-387-88370-0_7.

[30] A. M. Lokman, "Kansei/affective engineering and Web design," in Kansei/Affective Eng., ch. 8, Florida, USA: CRC Press, pp. 227-251, 2010.

[31] S. Ishihara and K. Ishihara, "Psychological Methods of Kansei Engineering," in Kansei/Affective Eng. ch. 3, Florida, USA: CRC Press, pp. 31-38, 2010.

[32] R. A. Johnson, and D. W. Wichern, Applied Multivariate Statistical Analysis, New York, USA: Pearson, 2007.

[33] A. F. M. Alkarkhi and W. A. A. Alqaraghuli, Easy statistics for food science with R, Cambridge, UK: Academic Press, 2018.

[34] F. Redzuan, A. M. Lokman, and Z. A. Othman, "Kansei semantic space for emotion in online learning," 2014 3rd Int. Conf. User Science and Engineering (i-USEr), 2014, pp. 168-173, doi: 10.1109/IUSER.2014.7002697.

[35] S. Zubir and F. Redzuan, "Evaluating students' emotional response in mobile learning using Kansei engineering," in International Conference on Kansei Engineering \& Emotion Research, pp. 801-810, 2018, doi: 10.1007/978981-10-8612-0_83.

[36] M. Nagamachi, Kansei Engineering, 2 Volume Set. Florida, USA: CRC Press, 2010.

\section{BIOGRAPHIES OF AUTHORS}

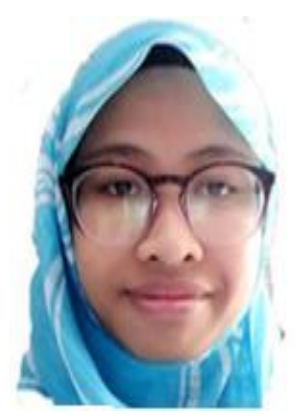

Farah Asyikin Jasmy is a Quality Assurance Engineer at Connexion Sdn Bhd. She has Bachelor of Information Technology (Hons) in Information Systems Engineering. She graduated from University of Technology of MARA Jasin, Malacca.She lives in Petaling Jaya, Selangor. 


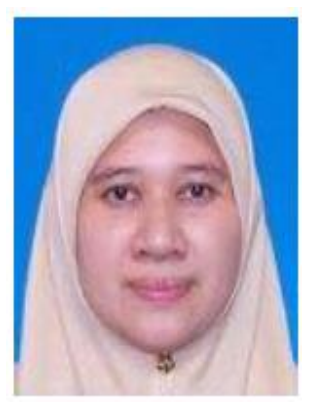

Dr Fauziah Redzuan holds Doctor of Philosophy in System Science and Management from Universiti Kebangsaan Malaysia (UKM) and Master of Science in Information Technology from Universiti Sains Malaysia (USM). She has been teaching in Universiti Teknologi MARA UiTM for 18 years in Information Technology field. Her research interest is related to Emotional/Affective E-Learning Design and kansei/Affective Engineering.

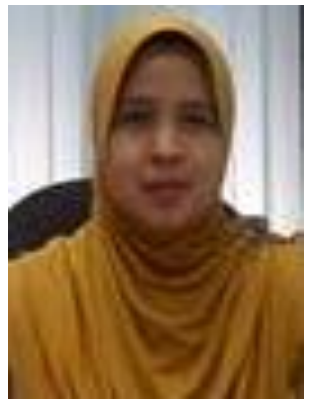

Dr Rogayah Abdul Majid holds Doctor of Philosophy in Information Technology from Universiti Teknologi MARA (UiTM) and Master of Science in Information Technology from Universiti Teknologi MARA (UiTM). Her research interest is related to HCI and E-Learning.

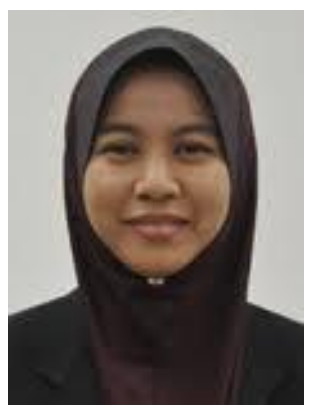

Dr Norisan Abdul Karim holds Doctor of Philosophy in Information Technology from Universiti Teknologi MARA (UiTM) and Master of Science in Information Technology from Universiti Teknologi MARA (UiTM). Her research interest is related to HCI. 